\title{
SUSTAINABILITY ISSUES WHEN THE FABRIC OF COASTAL CITIES FACE NEGATIVE TOURISM IMPACTS: A CASE STUDY IN LISBON, PORTUGAL
}

\author{
JOÃO-MANUEL CARVALHO \& SABRINA BERTOL \\ Universidade de Lisboa, Faculdade de Arquitectura, CIAUD, Portugal
}

\begin{abstract}
The urban fabric of historical western European coastal cities is a main magnet for tourists' attraction. The urban history has, however, imprinted specificities on urban space which derive from coastal location, such as features to protect the inland urban territory from undesirable invaders, or a dense urban grid around the harbour where business opportunities were concentrated. Those spatial specificities bring sustainability problems of their own when the oldest coastal urban areas become tourism accommodation areas with lots of restaurant and bar-like facilities at street level. Municipal measures that limit tourism activities in central historical coastal cities have already been issued, with a generalist approach. Those measures should however rely upon a detailed knowledge of the features tourism may threaten. A weighted check-list could be welcome and that is the subject of the present paper.
\end{abstract}

Keywords: coastal cities, sustainability, urban morphology, building typologies, urban problems.

\section{INTRODUCTION}

Tourism has become a twofold issue throughout historical European cities, since it enhances business but may have a negative impact on resident's welfare. This impact thus impinges on the sustainability of tourism destinations on welfare grounds [1]. Sustainability issues derived from tourism demand have been and tend to be studied as environmental and social issues, but they have a spatial reference that influences their origin and intensity which is not commonly acknowledged. This spatial reference is the issue of the present paper. It gets a technical importance when - as has previously happened in Barcelona, Berlin and Lisbon to counter what is seen as an excessive incidence of tourism in urban areas, the supply of tourism accommodation is restricted in some areas. Which are the relevant area boundaries for the purpose and what specific problems do the spatial features generate? Why restrict the tourism business of the property owners in those areas and not in other urban areas which adjoin the areas with restrictions? The rationale for the boundaries could rely on urban morphology and building features. This raises the question "how do urban morphology and building features relate to sustainability when tourism is a concern?" The answers could provide for a new role of urban and architectural analysis in urban policies.

\section{LITERATURE REVIEW}

Tourism demand is driven by a wide range of factors, of which we address the historical character of cities [2], namely those which history originates in a coastal location. Within that universe, the prevailing approaches to urban problems derived from a high tourism incidence belong into urban geography (the object being the urban system as a whole) [2], [3], into urban planning (again mostly under a global city approach and not specifically concerned with urban design issues [4]), into urban management (with an emphasis on urban conservation - one of the first explicit mentions to sustainability issues, within our theme, dating from the late 1990's [3] - traffic, urban regeneration and historic city modelling [2][4]) and, quite expectably, into tourism business (through concerns with product definition 
and competitiveness [3], [4]). The negative externalities of the corresponding tourism enhancement policies, even if mentioned, are not duly weighted in those prevailing approaches. More recent approaches, as related to the Airbnb-like accommodation incidence, start dealing with the negative effects of urban tourism on residents' welfare [5]. However, through all these approaches the spatial features of historical urban areas are dummy issues, i.e., urbanism (as different from urban planning) and architecture seem not to have been given a role in the analysis of the on-site negative effects of a tourism high incidence (perhaps because the latter is a recent phenomenon in most cities). As stated above, we consider that it is expectable that both analysis and problem solution may usefully refer to the detailed spatial features of historical urban areas.

\section{AIM AND METHODOLOGY}

The main research concern of this study is to develop a methodology that could explicitly integrate spatial features, namely urban morphology and building typologies, into urban policies decisions. The methodological steps for that purpose rely first on building an operational approach to urban morphology (through plan analysis and urban layout geometrics) and to building typologies (through information on structure type, lot size and fenestration rhythms) that allows for area delimitation and characterization; second on identifying problems derived from a high tourism incidence that impinge on residents' welfare, on heritage conservation, on safety and on public space maintenance in each urban zone previously bounded; and third on naming concerns that should be dealt with in urban policies through space-referred measures. Operational concepts within the urban morphology [6] and building typologies scope should be derived from theory, whereas problems would be identified through empirical work by listening to stakeholders and observing in loco.

\section{URBAN MORPHOLOGY TYPES, BUILDING TYPOLOGIES AND RELATED PROBLEMS IN COASTAL CITIES CENTRAL AREAS}

The chosen approach to urban morphology is based on the relationship of the physical parts of the urban environment and not on its abstract representation (e.g., topological models as in Space Syntax approaches). Urban morphology is therefore concerned with the form of the urban environment as given by its external parts, called morphological elements, which relate to each other. Morphological elements both allow for and derive from the analysis of the urban space and comprehend the pavements, the plots, the facades, the layouts, the streets, the trees, the urban furniture, the buildings, the blocks, the squares, the green areas, the patios and the monuments [7]. The very existence (or inexistence) of some of these elements may be a specific feature of an urban morphology type. Coastal cities may provide for specific relationships of morphological elements through itineraries from the mediaeval harbour areas or wall gates to more recent urban areas. The specificity would be the support of the urban morphology type. The approach through the visual configuration of the plan (e.g., as given by aerial view software) allows for quantifying (e.g., metrics) the relationship of plots, layouts, blocks, green areas, trees and squares, though mostly leaving aside (for direct approaches) elements such as pavements, facades, buildings, patios and monuments. Facades and buildings should furthermore be dealt with through selected features that have a direct relationship with the exterior urban space, namely height/shadow effect, front width/intersection effect and image impact/externality effects.

The ancient harbour areas tend to be organized along a major axis that connects the harbour to the hinterland; the axis configuration and its ramifications have been conditioned by the existence of defensive walls (besides other features we can deal with on a ceteris paribus ground) [8]. All this makes for original highly valued sites that mostly generated 
small plots and narrow streets with compact built fronts. Along these fronts the facades are very narrow except for palatial or administrative buildings located along the major axis where it sometimes enlarges to form squares. Green areas are very rare and pavements tend to be stone slabs of different sizes and rock type. Each building structure counts on the one of the adjoining buildings and is mostly wooden. Expected spatial sustainability problems derived from a high incidence of tourism, expressed as either daily visitors or hotel-like accommodation, therefore are: i) Pedestrian traffic is jammed; ii) Access, to and from buildings, conflicts with pedestrian traffic; iii) Emergency accessibility is very weak; iv) Public leisure sites are rare and people tend either to concentrate in excessive numbers in small squares or use inadequately any other space for that purpose; v) Building risks increase since buildings start supporting loads that they were not designed for; vi) Traditional pavements may need intervention as they become dangerous through under-visibility due to overcrowding; vii) Walls of heritage buildings get damaged through undue uses (e.g., leaning to them, graffiti for fun by drunk passers-by, etc.). 16th, 17th and 18th century expansions of the harbour nucleus tend not to be installed along the shore since enemy attacks keep being a threat (ceteris paribus for the other factors, e.g., windy shores); the harbour-inland axis and its ramifications are therefore the network support for the expansion. These later layouts are different however, with larger major streets and with squares that gain a new role as public spaces for social interaction and political affirmation - monuments and artistically designed useful features (e.g., fountains) define the urban itineraries that prolong the ancient harbour city. Urban design rationales provide for larger plots and buildings and give a new importance to intra-urban transportation, which translates into better pavements. The history of big urban fires led to safer roads and construction systems. Expected spatial sustainability problems derived from a high incidence of tourism, expressed as either daily visitors or hotel-like accommodation, therefore are: i) Intense undue use of artistic urban items as leisure and resting places; ii) Damage to some types of pavements (e.g., marble slabs); iii) Overuse of buildings not structurally designed to bear loads derived from an increased number of dwellings; iv) Urban image altered (e.g., through uses of balconies and front windows for purposes normally reserved for the back facades of buildings, but required when the number of tourism accommodations increases); v) Public transportation traffic becomes difficult in pedestrian jammed main itineraries; vi) Loss of intra-urban connectivity rationale of the coastal city since the urban network previously based on the harbour-inland axis becomes a problem requiring a by-pass. Some late 18th and 19th century expansions may further on retake advantage of shore locations since construction progresses allow for wide embankments and since sporadic enemy attacks become rare. New residential urban expansions (some of them with an original high-market second-residence character) create non-harbour urban coastal sites that encompass isolated historical buildings already located in those coastal areas best sites. These settlements benefit from urban design rationales that remain valid in our times. Mostly waterside urban areas are very attractive for tourists' leisurely promenades and monument visiting and get very crowded along the day though not so much at night, since the former go on being residential areas for the local inhabitants. However, streets lose their pure residential features because building floors at street level are densely occupied by restaurants and bars and overuse comes to previously existing quiet green public spaces. Though these settlements seem to have more ability to shelter a high incidence of tourism than previous urban layouts, spatial problems arise i) from more crowded public spaces along main streets or between intra-urban transport hubs, which becomes a frequent feature since normally not originating tourism-targeted measures, for not coinciding with rush hours; and ii) from conflict with the residential use. 


\section{ASSESSING SPACE-RELATED TOURISM PROBLEMS IN LISBON}

\subsection{Central Lisbon urban layouts}

The Lisbon urban plan [9] divides, for the purpose of specific urban norms, the city urban layouts into four models: layout A for ancient historical areas; layout B for planned layout (orthogonal grids); layout C for non-planned, non-historical areas (mostly 20th century "free" settlements); and layout D for planned 20th century low density settlements. The areas of concern for this paper entirely correspond to layouts A and B, though layout A comprehends more than one category, namely: i) the initial areas around the historical harbour and adjoining the defensive walls; and ii) the first expansion non-orthogonal layouts. Layouts Ai, Aii and B can be illustrated respectively by Fig. 1 (Alfama), Fig. 2 (Graça) and Fig. 3 (Baixa).

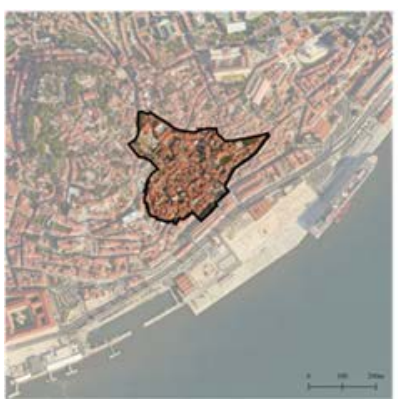

Figure 1: Alfama.

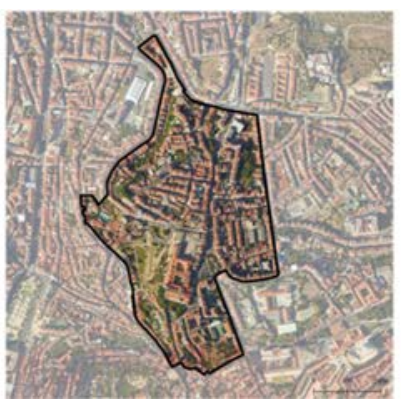

Figure 2: Graça.

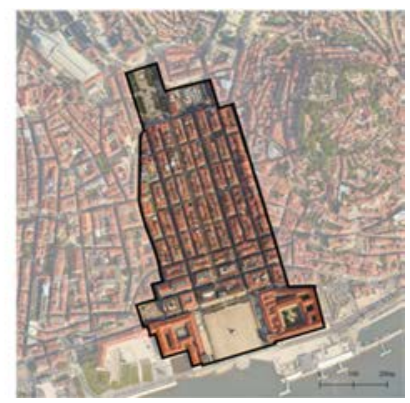

Figure 3: Baixa.

For the purpose of our research we will resort to a bonna fide selection of representative areas within those three layouts, which correspond to Figs 4-6.

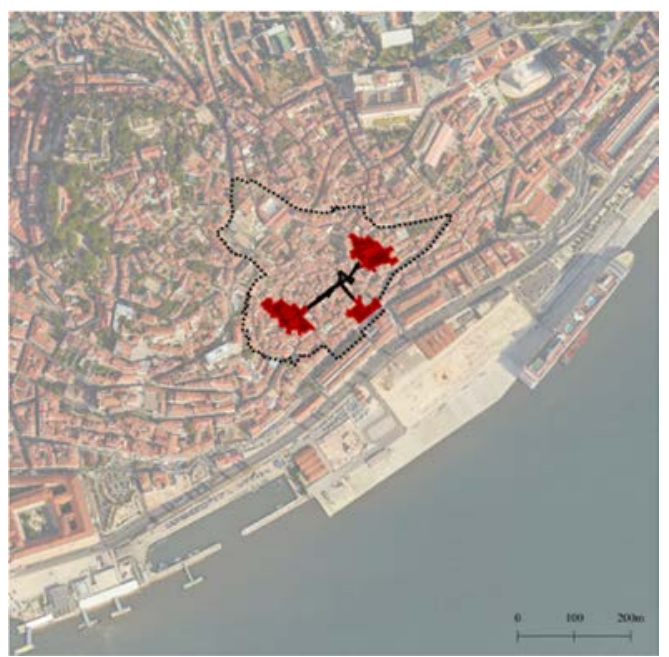

Figure 4: Ai (Alfama) - R. de S. Miguel, Bc. Mexia, Lg. de S. Miguel, Lg. do Chafariz de Dentro and Lg. de St. Estêvão. 


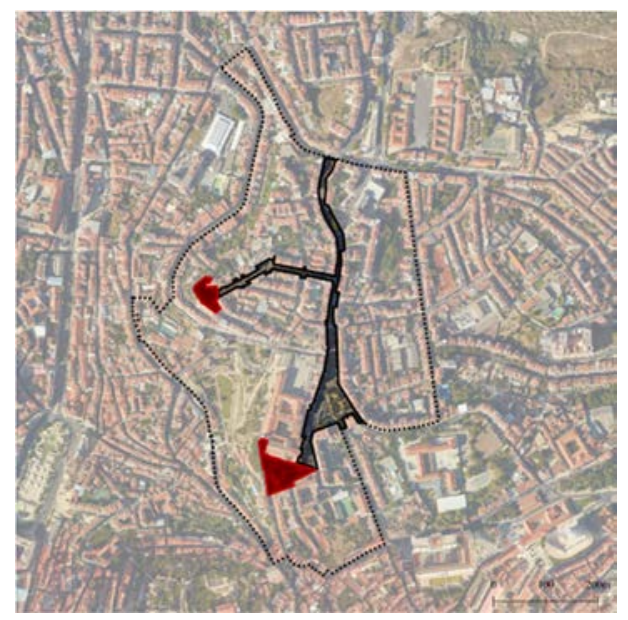

Figure 5: Aii (Graça) - R. Senhora do Monte, R. da Graça, Miradouro da Senhora do Monte and Lg. da Graça.

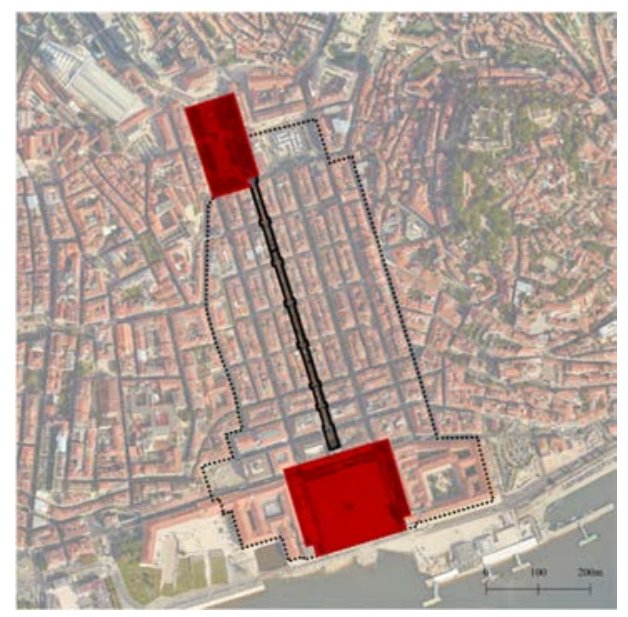

Figure 6: B (Baixa) - R. Augusta, Pç.do Comércio and Rossio.

\subsection{Spatial related problems derived from tourism incidence}

Tourism incidence in the abovementioned layouts has been measured through the incidence of local accommodation (AL "Alojamento Local"), which is a form of accommodation well represented by Airbnb-like ventures. This choice derives from considering AL as the utmost expression of tourism pressure on urban layouts (correlation between AL incidence and visitors' numbers tends to be high). The incidence of AL is given by the ratio between the number of AL addresses and the total number of dwellings; it refers to the area selected as representative of the layout type. The measured incidences - taken as high ones by the urban authorities and also when compared with Lisbon 19th and 20th century layouts - are presented in Figs 7-9. 


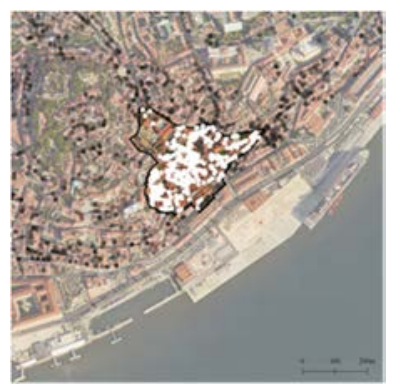

Figure 7: AL incidence at Ai Alfama. Dwellings: 1,579, AL: 775 (49.08\%), Area: $0.07 \mathrm{~km}^{2}$.

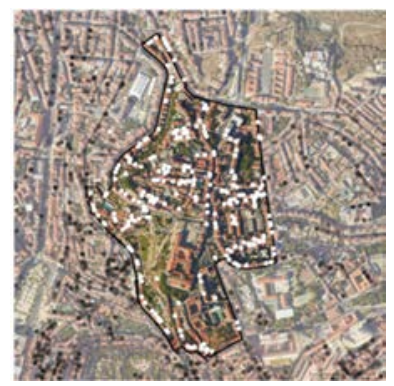

Figure 8: AL incidence at Aii Graça. Dwellings: 3,431, AL: 501 (14.6\%), Area: $0.30 \mathrm{~km}^{2}$.

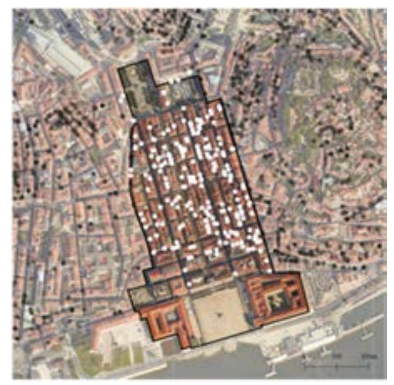

Figure 9: AL incidence at B Baixa. Dwellings: 1,392, AL: 803 (57.68\%), Area: 0.29 km².

The expected problems as listed above were analysed in loco through site visiting, to check their existence and features. The category outcomes and the illustration of on-site problems are presented below in Table 1 and Figs 10-18.

5.3 Weighting the problems through stakeholders' surveying

A check-list with the expected problems (Table 1) was introduced to local stakeholders noncommitted to tourism businesses (mostly cultural associations or local government agencies' employees), for each one of the three relevant urban morphology types (i.e., Ai, Aii and B). 
Table 1: Expectable tourism incidence problems.

\begin{tabular}{|l|c|c|c|}
\hline & Layout Ai & Layout Aii & Layout B \\
\hline Pedestrian traffic & $\mathrm{XX}$ & $\mathrm{X}$ & $\mathrm{X}$ \\
\hline Access to buildings & $\mathrm{XX}$ & $\mathrm{X}$ & \\
\hline Pavement risks & $\mathrm{XX}$ & $\mathrm{X}$ & $\mathrm{X}$ \\
\hline Emergency accessibility & $\mathrm{XX}$ & $\mathrm{X}$ & \\
\hline People concentrations & $\mathrm{X}$ & $\mathrm{X}$ & $\mathrm{X}$ \\
\hline Building risks & $\mathrm{XX}$ & $\mathrm{X}$ & $\mathrm{XX}$ \\
\hline Heritage damages & $\mathrm{X}$ & $\mathrm{X}$ & $\mathrm{X}$ \\
\hline Public transportation traffic & $\mathrm{X}$ & $\mathrm{XX}$ & $\mathrm{XX}$ \\
\hline Urban image & $\mathrm{XX}$ & $\mathrm{X}$ & \\
\hline Urban segregation problems & $\mathrm{X}$ & & \\
\hline Conflicts with residential use & $\mathrm{XX}$ & $\mathrm{X}$ & \\
\hline Overcrowded city routes & $\mathrm{XX}$ & $\mathrm{X}$ & $\mathrm{XX}$ \\
\hline
\end{tabular}

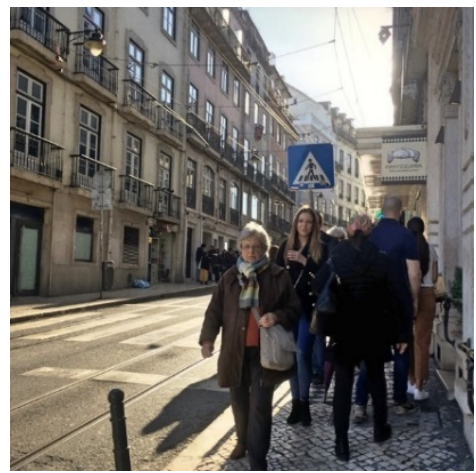

Figure 10: Pedestrian traffic - R. do Loreto (Aii).

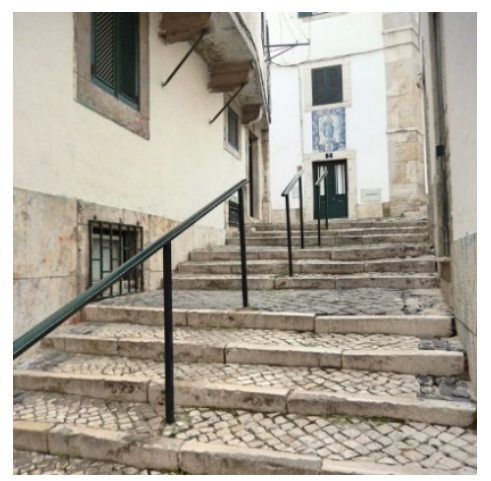

Figure 12: Pavement risks - Beco Cruzes (Ai).

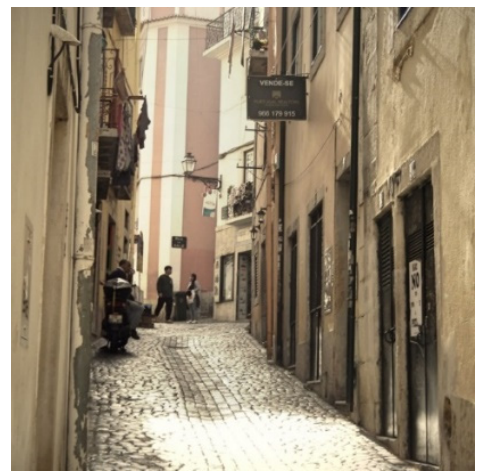

Figure 11: Access to buildings - R. de S. Miguel (Ai).

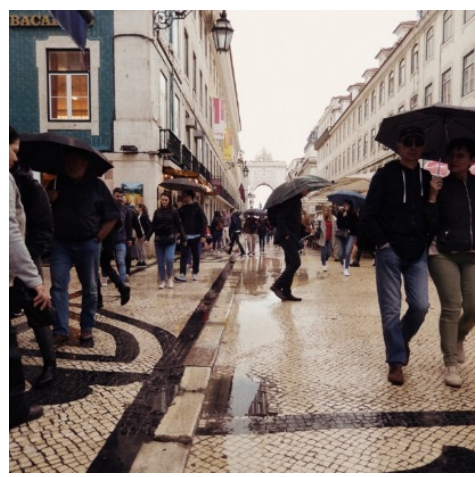

Figure 13: Pavement risks - Augusta (B). 


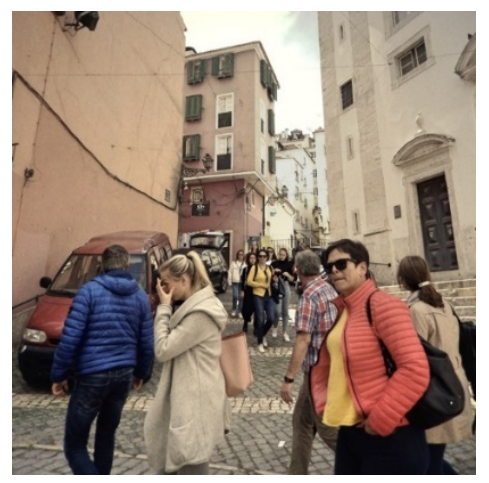

Figure 14: People concentrations - Lg. de S. Miguel (Ai).

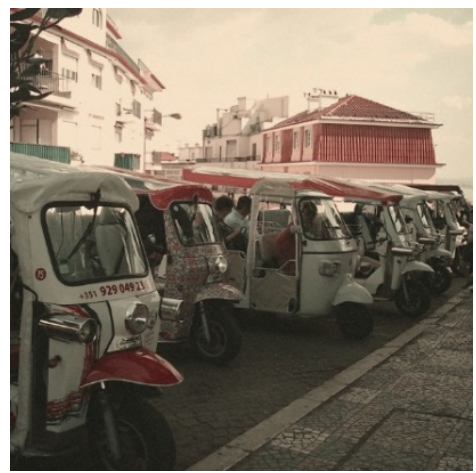

Figure 16: Urban image - Miradouro Senhora do Monte (Aii).

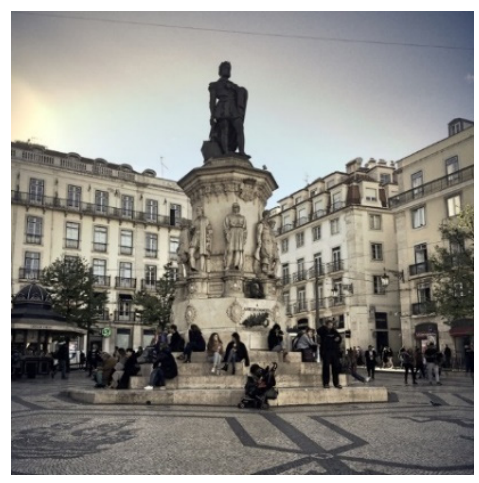

Figure 15: Heritage damages - Pç. Luís de Camões (Aii).

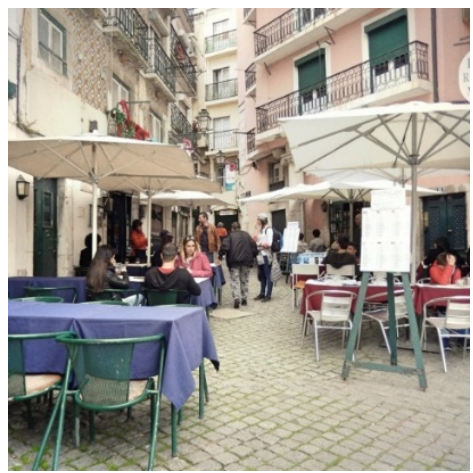

Figure 17: Urban image - Lg. Chafariz de Dentro (Ai).

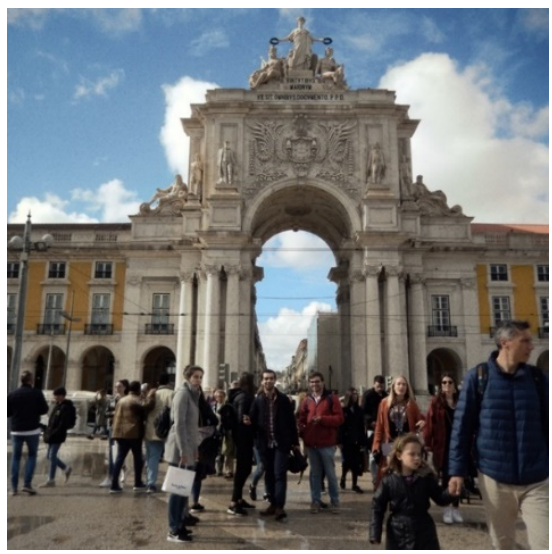

Figure 18: Overcrowded city routes - Praça do Comércio (B). 
The interviewer was an architect able to explain the issues and to insert the former's opinions and comments into previously considered categories. The resulting profile for each urban morphology type is presented in Table 2 below. The results of the survey went beyond the initial purpose (problem identification and weighting) as they also allowed for a further definition of the initially expected problems according to the urban morphology types, e.g., senior people slow mobility on streets full of tourists, or the former difficult access to overcrowded public transportation, have been dealt with as "pedestrian traffic" or "urban segregation" issues, but deserving further detail.

Table 2: Average weighted stakeholders' concerns with tourism incidence.

\begin{tabular}{|l|c|c|c|}
\hline & Layout Ai & Layout Aii & Layout B \\
\hline Pedestrian traffic & 1.7 & 0.7 & 1.0 \\
\hline Access to buildings & 2.0 & 1.0 & 0.5 \\
\hline Pavement risks & 2.0 & 0.7 & 0.8 \\
\hline Emergency accessibility & 1.7 & 0 & 0 \\
\hline People concentrations & 1.7 & 0.7 & 1.0 \\
\hline Building risks & 1.7 & 0.7 & 0.8 \\
\hline Heritage damages & 0 & 0.3 & 0.3 \\
\hline Public transportation traffic & 0 & 0.7 & 1.0 \\
\hline Urban image & 2.0 & 1.0 & 1.0 \\
\hline Urban segregation problems & 2.0 & 1.3 & 0.5 \\
\hline Conflicts with residential use & 2.0 & 0.3 & 0.3 \\
\hline Overcrowded city routes & 2.0 & 1.0 & 1.5 \\
\hline
\end{tabular}

The above indicators aim at representing problems directly derived from urban morphology and general building risks, when the incidence of tourism is very high. They were introduced to the interviewed stakeholders as expectable problems caused by tourism at historical urban areas with specific spatial features. Each indicator was introduced with an explanation, namely: i) Pedestrian Traffic as the ease of circulation in the public space; ii) Access to Buildings as the unimpeded entrance or exit from residences; iii) Pavement Risks as the safe pedestrian circulation on traditional pavements; iv) Emergency Accessibility as the unimpeded access of security vehicles or equipment; v) People Concentrations as the possibility of comfortably and safely enjoying valued public spaces; vi) Building Risks as the possibility of accidents related to building occupation or transformation (generally assessed without regard for typology); vii) Heritage damages as the frequency of small systematic damages to monuments or prized urban elements; viii) Public Transportation Traffic as the level of service as given by access to bus lines, by bus frequency, by availability of seat and by the buses ease of circulation; ix) Urban Image as the unintended transformation of public spaces as well as of the private spaces interface with the public space; $\mathrm{x}$ ) Urban Segregation as the feeling of residing or working in an area disconnected from the urban residents' community; xi) Conflicts with Residential Use as the tourism negative effects that make life uncomfortable for permanent residents (e.g., noise); xii) Overcrowded City Routes as local itineraries that became dysfunctional passing routes for a lot of non-residing individuals. The profile of the relevant list of problems tends to differ along the urban typology types, namely for non-existent issues (neither heritage damages nor public transportation problems are mentioned at Ai; emergency accessibility is neither mentioned at Aii nor at B), or for major concerns (all the assessed categories but with a weaker concern 
for emergency accessibility, people concentrations and building risks, at Ai; urban segregation problems, access to buildings and overcrowded city routes, at Aii; overcrowded city routes, pedestrian traffic, people concentrations, public transportation traffic and urban image at B). All types have anyway in common relatively strong concerns with pedestrian traffic, access to buildings, pavement risks, people concentrations, building risks, urban image, urban segregation problems and overcrowded city routes. The abovementioned evidence widely fits the expected problems assigned to each type of urban morphology derived from the generic historical evolution of the coastal city.

\section{CONCLUSIONS AND RECOMMENDATIONS: CAN MEASURES TO CONTAIN TOURISM IN COASTAL CITIES BENEFIT FROM DETAILED INFORMATION CONCERNING URBAN LAYOUTS?}

\subsection{Additional comments to the approach and further research}

The measures to contain tourism incidence under sustainable urban management strategies tend to be based on administrative boundaries and on politically sensitive social issues, without explicit reference to urban spatial features. The problems derived from a high tourism incidence are very important in historical cities, of which coastal cities are a relevant category. For the purpose of allowing the abovementioned measures to be referred to boundaries that rely on spatial features we resorted to a generalist model of the evolution of the coastal city urban morphology. To each basic type of urban morphology derived from that evolution, specific tourism-related sustainability problems could be assigned, which we did on a tentative basis. To experiment a methodology for identifying sustainability spacerelated tourism problems in a given coastal city (Lisbon) we further-on used a basic problem list derived from the generalist model, but referring it to specific (i.e., Lisbon) urban morphology types, withdrawn from the city urban plan. Those types were sampled to smaller representative areas where tourism incidence is high (as measured by the ratio of tourismallocated dwellings to total dwellings), so that problems could be checked on-site in a practical way. This allowed for presenting a list of problems for comments and importanceweighting to a few selected stakeholders non-committed to tourism businesses. The approach to existing buildings sustainability risks by building typology, derived from high tourism incidence, is a feasible aim which could not however be addressed in this first approach (risks to buildings were approached but without addressing their typology). The experiment thus conducted for: i) Detecting the relevance of urban spatial features in supporting area-based tourism incidence containment; and ii) Building-up a feasible purposeful methodology, allowed for identifying sustainability problems that should be in the mire of regulators whenever historical urban morphology types are put under pressure by high tourism incidence. For the dense areas built around the historical harbours at a time when defensive concerns mattered (Ai) prevailing physical problems tend to be the access to buildings and the pavement risks, while space-related socio-cultural problems tend to be the urban image, the urban segregation problems, the conflicts with residential use and the overcrowded city routes. For the inner areas of the first city expansions exterior to defensive walls (Aii) prevailing problems tend to be of the space-related socio-cultural nature, namely urban segregation problems and overcrowded city routes, while on the physical side access to buildings is the most rated category. For planned urban historical expansions (B) mobility seems to be the most relevant concern, namely with overcrowded city routes, pedestrian and public transportation traffic problems and public concentrations, though the latter might be related to heritage damage risks and to the urban image. The different urban morphology 
types therefore have different profiles when tourism incidence problems arise, even if all the categories that represent the expected problems may be seen as common concerns in all three urban morphology types, with the exception of emergency accessibility (not a concern at Aii and B) and of either heritage damages or public transportation traffic (not concerns at Ai). The experiment illustrates a possible pragmatic (and with a quite positive net marginal value for information) method for designing more efficient approaches to tourism containment regulation whenever space should be taken into due consideration. Urban morphology types and their sampling for our purpose, analysis categories, stakeholders' profiles and number, as well as building typologies, should be the target of further research for the procedure to be of use by regulators.

\subsection{Possible measures to deal with the assessed problems}

The outcomes of the experiment allow for a more targeted regulation when dealing with tourism incidence problems at spatially bounded urban areas, namely in coastal historical cities. Dense historical areas close to the harbour may require a more detailed regulation on the management of pedestrian routes, on the constraints on tourism accommodation by street, on signposting for historical pavements that bear risks for users, on safeguarding emergency accessibility and on avoiding segregated streets. These areas tend to benefit from heritage protection as a whole and therefore individual items are safeguarded and changes are countered; space management, either at public or private level, is a core issue. The nonorthogonal grid first historical expansions seem as well to require a special attention on the management of pedestrian routes and on the easiness of the access to buildings, but with a stress in the control of the urban image and on the preservation of the authenticity of urban life - these are vulnerable areas as far as either a strong urban image or a functional vocation is concerned; the road network connections to the historical central city seem to be an issue to deserve a particular attention. Designed expansions based on orthogonal grids require a careful integration into the city traffic and public transportation networks besides the local management of pedestrian routes and the fitting of selected public spaces for the concentration of tourists - these areas go on having a functional articulation with the modern city and main public transport routes run along them; the relationship between quality public space and the overall city mobility could be a major domain of concern. At each and all of the three considered historical urban layouts pavement risks are envisaged as an issue; this may of course derive from the specificity of Lisbon traditional public pavements (Figs 12 and 13), that are costly to maintain (and are therefore often irregular) and sliding-prone by nature (though environment-friendly for being semi-permeable), requiring an watchful pedestrian eye. However this issue is also relevant in other historical cities (e.g. the marble pavement of the main Dubrovnik street). Revised pavements at historical urban areas, to meet dense tourist traffic, reduce risks but within a trade-off with urban image (Fig. 17 when compared to Fig. 13). Defining norms to building interventions by typology and providing for an architectural guide for all types of interventions that relate to building safety, to their relation with the public space and to the latter features seem anyway relevant measures for all the urban morphology types considered.

\section{REFERENCES}

[1] DG Enterprise and Industry, European Tourism Indicator System. Toolkit for Sustainable Destinations, European Union: Brussels, 2013.

[2] Asworth, G. \& Tunbridge, J., The Touristic-Historic City: Retrospect and the Prospect of Managing the Heritage City, Routledge: London, 2011. 
[3] Jansen-Verbeke, M. \& Lievois, E., Analysing heritage resources for urban tourism in European cities. Contemporary Issues in Tourism Development, eds D. Pearce \& R. Butler, Routledge: London, pp. 81-107, 1999.

[4] Russo, A. \& van der Borg, J., Planning considerations for cultural tourism: A case study of four European cities. Tourism Management, 23(6), pp. 631-637, 2002.

[5] Tokarchuk, O. et al., Development of city tourism and well-being of urban residents: A case of German Magic Cities. Tourism Economics, 23(extra 2), pp. 343-359, 2017.

[6] Coelho, C., Cadernos de Morfologia Urbana. Estudos da Cidade Portuguesa - Os Elementos Urbanos, Vol I. Argumentum: Lisbon, 2013.

[7] Lamas, J., Morfologia Urbana e Desenho da Cidade, Fundação Calouste Gulbenkian: Lisbon, 2010.

[8] Mumford, L., The City in History, Penguin: London, 1977.

[9] CML, Plano Director Municipal de Lisboa, Câmara Municipal de Lisboa: Lisbon, 2012. 